\title{
TESTAMENTOS DE INDÍGENAS AMERICANOS SIGLOS XVI - XVII
}

\author{
Pablo Rodríguez \\ Professor, Universidad Nacional de Colombia \\ Pesquisador, Universidad Externado de Colombia
}

\section{Resumo}

Este artigo pretende explicar o significado e as características dos testamentos indígenas registrados em diferentes regiões da América espanhola. A fonte principal do estudo são coleções documentais de testamentos publicadas no México, na Colômbia e no Chile. Também utiliza os estudos historiográficos que, com base nesses documentos, foram realizados no Equador e no Peru. $\mathrm{O}$ artigo abre uma nova janela à compreensão dos complexos processos econômicos, sociais e culturais vividos pelos povos indígenas a partir da conquista.

\section{Pallavras-Chave}

Testamento $\bullet$ Indígenas $\bullet$ Confraria $\bullet$ Mestiçagem • Migração

\section{Abstract}

This article explores the meaning and characteristics of Indians' wills, recorded in the notary offices of different regions in the Americas. The main source of study are the documentary collections of wills published in Mexico, Colombia and Chile. The article also draws support from studies based on documents written in Ecuador and Peru, opening a new window for the comprehension of the complex cultural, social and economic processes the indigenous populations went through due to the conquest period.

\section{Keywords}

Testament $\bullet$ Indigenous $\bullet$ Brotherhood $\bullet$ Mestizaje $\bullet$ Migration 
Entre el año 1998 y el 2002 fueron publicadas tres importantes colecciones de testamentos de indígenas, sin que hicieran parte de un proyecto concertado. Primero, en México aparecieron tres volúmenes que compilan 161 testamentos de indígenas de los siglos XVI, XVII y XVIII, escritos originalmente en nahuatl, mixteco, otomí, zapoteco y castellano. Se trata de una edición bilingüe coordinada por Teresa Rojas, investigadora del instituto Ciesas, acompañada de importantes apéndices e índices analíticos ${ }^{1}$. Luego, en Santiago, Don Julio Retamal publicó un volumen con la transcripción de 100 testamentos de indígenas $^{2}$. Finalmente, en Bogotá, este autor editó un libro que compila la transcripción de 96 testamentos de indígenas de los siglos XVI y XVII ${ }^{3}$. Estas tres publicaciones conforman un conjunto documental de extrema significación, especialmente para intentar efectuar nuevas observaciones sobre los cambios vividos por las sociedades indígenas americanas a raíz de la conquista ${ }^{4}$.

La coincidencia de estas publicaciones probablemente corresponde a la localización, lectura y alta valoración de estos llamativos documentos ocurrida en el último decenio del siglo XX. Efectivamente, durante estos años, distintos historiadores y antropólogos de diversas partes de América llevaron a cabo intensas investigaciones intentando comprender bajo una visión no esquemática los complejos procesos vividos por las sociedades indígenas bajo el dominio español. Se reconoce como el principal y más antiguo inspirador de esta renovación historiográfica a Charles Gibson, cuya obra buscó descubrir, a través de nueva documentación, los hechos sociales existentes tras la espesa capa de las instituciones coloniales hispánicas ${ }^{5}$. El enorme mérito de la obra de Gibson fue develar el funcionamiento de instituciones como la encomienda, la mita y

\footnotetext{
${ }^{1}$ Estos 161 testamentos corresponden a un conjunto de 1296, localizados por estos investigadores en los archivos mexicanos y bibliotecas norteamericanas. Ver: ROJAS RABIELA, Teresa; LETICIA REA, Elsa y otros. Vidas y bienes olvidados: testamentos indígenas novohispanos. 3 vols. México: Ciesas, 1999.

${ }^{2}$ RETAMAL ÁVILA, Julio. Testamentos de indios en Chile colonial, 1564-1801. Santiago: Universidad Andrés Bello, 2000.

${ }^{3}$ RODRÍGUEZ JIMÉNEZ, Pablo. Testamentos indígenas de Santafé de Bogotá, siglos XVIXVII. Bogotá: Instituto Distrital de Cultura y Turismo, 2002.

${ }^{4}$ Extrañamente, y por razones que desconozco, no se han llevado a cabo hasta el momento (2006) este tipo de publicaciones sobre los indígenas de Cuzco y Lima, dos escenarios centrales de la historia americana.
}

${ }^{5}$ GIBSON, Charles. Los Aztecas bajo el dominio español. México: FCE, 1967. 
la hacienda; de insistir en el dinamismo de los pueblos indios, sin ocultar sus patrones de desigualdad, y también, de reparar en el vinculo ciudad-campo en la transformación social y política de la comunidad indígena. Este esfuerzo estuvo apoyado esencialmente en una apropiación de nueva documentación, más acorde con la historia social. Pleitos y litigios de tierras, juicios civiles y criminales, y un amplio repertorio de documentos que informaban sobre la vida en los pueblos de la meseta central de México, le llevaron a Gibson a indicar que el futuro de la historia colonial estaría dado por el hallazgo y utilización de documentos más cercanos a la vida de la gente de la época.

Esta orientación fue retomada por James Lockhart, quien, podría decirse, concentró todas sus energías en lograr trascender las fuentes elaboradas por los colonizadores. Luego de su etapa peruana, en la que Lockhart estudió la sociedad creada por los conquistadores y sus propias biografías, trasladó sus inquietudes a la sociedad indígena mexicana de los siglos XVI y XVII. ${ }^{6}$ Los Nahuas después de la Conquista, su más ambiciosa y reciente obra, es una fina reconstrucción del universo indígena local ${ }^{7}$. El altépetl es la unidad básica indígena, donde Lockhart observa en forma detallada las continuidades y fracturas de la sociedad indígena colonial. Huelga decir, que ha sido Lockhart el historiador social que de manera más amplia y exitosa ha estudiado los testamentos coloniales, tanto de españoles como de indígenas. Estos últimos los ha analizado para comprender las transformaciones sensibles que tanto en cuestiones como la propiedad, el trabajo agrícola, la religión o la lengua vivieron los nahuas. Junto a Lockhart, un amplio número de historiadores latinoamericanistas han tomado los testamentos indígenas como base para analizar distintas sociedades locales o grupos sociales específicos. Algunos que deben nombrarse son S.L. Cline, F. Salomon, S. Kellogg y Jacques Poloni-Simard ${ }^{8}$.

${ }^{6}$ LOCKHART, James. El Mundo Hispanoperuano, 1532-1560. México: FCE, 1982; Los de Cajamarca: un estudio social y biográfico de los primeros conquistadores del Perú. 2 vols. Lima: Milla Batres, 1986.

${ }^{7}$ LOCKHART, James. Los Nahuas después de la conquista: historia social y cultural de la población indígena del México central, siglos XVI-XVII. México: FCE, 1999.

${ }^{8}$ CLINE, SALOMON, KELLOG e POLONI-SIMARD. Colonial Culhuacan, 1580-1600. Albuquerque: University of New Mexico Press, 1996. SALOMON, Frank. "Indian women of early colonial Quito as seen trough their testaments". The Americas, 44:3, 1988, pp. 325341. KELLOGG, Susan. Dead Giveaways: Indigenous testaments of colonial Mesoamerica and the Andes. Salt Lake City: The University of Utah Press, 1998. POLONI-SIMARD, Jacques. La mosaïque indienne. Mobilité, stratification sociale et métissage dans le corregimiento de Cuenca (Equateur) du XVIe siècle au XVIIIe siècle. Paris: EHESS, 2000. 
El presente texto tiene el propósito de explicar la naturaleza de los testamentos, su origen y sentido cultural. Sin embargo, de manera particular me interesa comentar el significado de los testamentos de indígenas de la época colonial. Buscaré explicar su carácter excepcional, en el contexto de una historia en la que han prevalecido esquemas de extrema marginación, sumisión y pasividad de los pueblos indígenas. Trataré de resaltar los aspectos que han permitido analizar, pero de manera especial, los potenciales futuros de investigación de nuevos temas de la vida social y cultural de los pueblos indígenas americanos.

\section{¿Pero, qué es un testamento?}

Es un documento peculiar, de origen medieval. En sus orígenes se trataba de un documento escrito en el que se hacía confirmación de fe y devoción cristiana. Un momento en el que los que estaban próximos a la muerte confesaban su fe y ponían su alma en paz. Confesaban sus pecados, reparaban los males cometidos y declaraban su última voluntad. El testador, igualmente preparaba su velo y entierro. En cierto sentido el testamento era la preparación para el viaje al más allá. Con acierto, Jacques Le Goff llegó a decir que el testamento era el "passeport pour le ciel". Con el tiempo, los testamentos fueron integrando asuntos paganos, como la declaración de bienes y su distribución entre los deudos. Una especie de relación mundana de los logros y beneficios económicos de las personas. De esta manera, los testamentos llegaron a reunir lo espiritual y lo material de la vida de los individuos.

El testamento es un documento sumamente solemne, recordemos que usualmente inicia con la expresión "In Nomine Dei", lo cual le da un elevado grado de veracidad. Y aunque debía ser registrado ante un escribano oficial, y ese evento debía ser confirmado por las firmas de testigos y deudos, muchas veces su escritura ocurría en circunstancias imprevisibles. Una fórmula común de los testamentos es el reconocimiento de lo impredecible de la muerte. Unos lo dictaban en el lecho de enfermos, otros lo escribían en la intimidad de su habitación y otros lo disponían en la oficina de un escribano. Sabemos que muchos no lo hacían por razones de vejez o enfermedad, sino en la proximidad de un viaje.

Igualmente, el testamento es un ejercicio de memoria. El testador aguza su memoria y trata de recordar los grandes y pequeños asuntos de su existencia.

${ }^{9}$ LE GOFF, Jacques. La bourse et la vie. Paris: Hachette, 1986, p. 65 
El testamento es una especie de pequeña biografía, una síntesis de la existencia de hombres y mujeres del pasado. Por ejemplo, nombra los padres y, en ocasiones, los abuelos. Y nos dice si es hijo legítimo o ilegítimo. Reconoce los matrimonios que tuvo, o si nunca se casó pero tuvo otras relaciones. Enumera los hijos, legítimos e ilegítimos, que viven o han fallecido. Así como los expósitos y huérfanos criados como hijos de la casa. También nombran los nietos. En fin, el testamento es una especie de genealogía personal. A ese parentesco también aparece vinculado el de amistades, afectos y padrinazgos. Un circulo que acompaña al de parientes, que lo fortalece, o, en ocasiones, lo reemplaza. En el testamento se nombran los grandes afectos por la esposa o los hijos, como también los desengaños y las amarguras. No son poco los testamentos en los que se reconoce el amor especial por un hijo o una hija, o en los que se lamenta la ingratitud de un hijo. En suma, los testamentos al ser escritos en la vejez, o en la proximidad de la muerte, nos dan una visión en perspectiva de la historia familiar.

Igual ocurre con el patrimonio. La persona recuenta sus bienes y dice cómo y de quién los adquirió. Además precisa a quien los destina. Reconoce sus deudas y enumera las cantidades y las personas que le deben. En ocasiones, el inventario de bienes sorprende por su minuciosidad. En la época preindustrial aun los más pequeños objetos tenían un enorme valor para la gente. Un cuchillo, una camisa o un vaso ameritaban nombrarse e inventariarse. El que se dedicara tanta atención al legarlos nos permite imaginar con cuanta satisfacción los recibía su beneficiario.

Además el testamento precisa una serie de hechos de carácter espiritual muy importantes. El testador, según su disponibilidad económica, destina partidas para misas por su alma. También aparte para limosnas a los pobres y obras pías. Este espíritu visible en los patrimonios y capitales que se destinaban a las instituciones eclesiásticas permitió estudiar a Ph. Ariés, M. Vovelle y P. Chaunu los procesos de intensificación y luego descristianización de la cultura de la muerte en Occidente.

En fin, un testamento es un documento rico en información sobre la existencia de un individuo como de su comunidad. Es un documento que liga lo público con lo privado de la vida de una persona. Esto hace de los testamentos materiales ricos en información económica, social, cultural y espiritual. Son documentos esenciales para observar en detalle grandes categorías sociales o culturales, y especialmente, la vida de las pequeñas comunidades. 


\section{¿Cuál es la estructura del testamento?}

Probablemente, en razón de su naturaleza, de su doble composición, espiritual y pagana, el testamento está dividido en dos partes de alguna manera visibles. La primera es la que podríamos llamar de fe, toda la primera parte constituye una afirmación religiosa. Esta parte también está conformada por los preparativos del velorio y el entierro. El testador dice: "Cuando Dios fuere servido llevarme de esta presente vida...". Indica la mortaja que desea, si quiere una misa cantada con cruz en alto y con presencia de clérigos. Si pertenece a una o varias cofradías el testador espera ser acompañado por su hermanos. Luego sigue una sección que podríamos considerar intermedia y que se destina a la relación personal y familiar. En ella, el testador nombra sus padres, su matrimonio y sus hijos. A continuación viene la segunda sección que consideramos patrimonial. Allí el testador hace inventario de sus bienes, de sus deudores y sus deudas. A la vez, es allí donde el testador distribuye sus bienes, tanto entre sus herederos forzosos (esposa e hijos), como entre sobrinos, nietos, esclavos y sirvientes. Como ya señalé, el testamento termina con el nombramiento de unos testigos y la firma del escribano.

La trascendencia e importancia social de los testamentos hicieron que se popularizaran entre la población ${ }^{10}$. Esto condujo a una cierta formalización de los testamentos. Para facilitar la tarea de los escribanos, y también, para asegurar el rigor de los testamentos, desde el siglo XVI fueron divulgados distintos modelos o machotes para su redacción. Tal vez, los más conocidos en la península y que tuvieron amplia difusión en América fueron la Suma del estilo de escribanos, de Lorenzo de Niebla, y la Primera parte de escrituras de Diego de Ribera $^{11}$. Incluso la primera, llega a decirse, pudo servir de ejemplo a Fray Alonso de Molina cuando redactó su afamado Confesionario Mayor en lengua mexicana

\footnotetext{
${ }^{10}$ Cabe agregar que la Iglesia estableció en el Concilio de Trento la obligatoriedad de los cristianos católicos de hacer testamento.

${ }^{11}$ Ver NIEBLA, Lorenzo de. Suma del estilo de escribanías y de herencia y particiones y escripturas y avisos de jueces. Sevilla: Martínez de Bañares, 1565. RIBERA, Diego de. Primera parte de escripturas y orden de partición y cuenta, y de residencia judicial, civil y criminal, con una instrucción a los escrivanos del Reyno al principio y su arancel. Granada: vendida por el mercader Juan de Montoya, 1596. [2ª . Edición, Bogotá: Biblioteca Nacional de Colombia].
} 
y castellana ${ }^{12}$. Podría decirse que estos modelos son especies de cuestionarios, formados por un número de entradas que siempre inician con la palabra Item.

Sin embargo, con todo el carácter formal que adquirieron los testamentos, poseen innumerables expresiones, en ocasiones incidentales. Dentro de su esquematismo, el testamento incorpora lo inasible, lo circunstancial y lo emocional. Se equivoca quien ve en los testamentos una documentación standard.

\section{Los testamentos de indígenas}

Como he dicho los testamentos son un producto de la cultura cristiana, católica, y del derecho castellano. En razón de su naturaleza tuvieron una amplia popularización entre hombres y mujeres. Y, a pesar de que poseen un aspecto patrimonial, éste no determino su elaboración. Los testamentos eran hechos por hombres y mujeres de todos los grupos sociales. Tanto los nobles y poderosos, como gente de condición media o muy modesta los hacían. Incluso, aquellos que se conocían como "pobres de solemnidad”, en razón de su mucho fervor cristiano hacían sus testamentos. En el momento de la conquista de América testar era una actividad corriente. Podríamos además considerar que con el auge del catolicismo y la prosperidad económica, los testamentos tomaron un mayor auge en el siglo XVI y no lo perderían hasta el siglo XIX. Así, los testamentos eran un componente importante de la cultura de los conquistadores que arribaron a América.

Los testamentos de indígenas debemos considerarlos parte del proceso de aculturación y miscegenación. Los distintos sínodos y concilios provinciales realizados en México, Lima, Santafé de Bogotá, y Quito conminaban a los clérigos a asistir a los moribundos y a motivarlos a hacer sus testamentos. En la difusión de los testamentos entre la población, tanto española como indígena, tuvo especial desempeño la iglesia católica, tanto a través de las órdenes regulares como de los seculares. Uno de los grandes propósitos de los religiosos era la salvación de las almas. Es decir que éstas alcanzaran el paraíso y tuvieran un descanso eterno. Religión que insistía con imágenes y descripciones en lo

\footnotetext{
${ }^{12}$ MOLINA, Fray Alonso de. Confesionario Mayor en lengua mexicana y castellana. México: Instituto de Investigaciones Bibliográficas-UNAM, Edición facsimilar, 1975. La primera edición ocurrió en 1565, y contiene una sección, en las dos lenguas, con un modelo de testamento para los indígenas mexicanos.
} 
terrible del infierno. Cabe recordar que el testamento es un preparativo para el momento de la muerte y el juicio final. Una frase de los testamentos recuerda que todos somos mortales. Este tema de la muerte, central y casi obsesivo en la religión de la época, explica que los religiosos hubieran insistido a los naturales en la necesidad de hacer sus testamentos. Una evidencia significativa de este hecho es la de que los testamentos aumentaron notablemente en las épocas de epidemias y hambrunas. Tres fechas memorables en Nueva España a este respecto son las de 1579, 1643 y 1737, cuando se presentaron agudas epidemias de viruelas, inundaciones y sequías ${ }^{13}$.

De otro lado, tal parece, al menos entre los azteca existía la tradición de testar. Es decir, en un acto solemne y verbal, los mayores cercanos a su muerte distribuían sus bienes y su dignidad entre sus parientes ${ }^{14}$. Existen códices y pictogramas en los que se representa, por ejemplo, la transmisión de mando. Así que los indígenas entendían muy bien la practica de testar, de legar. Y a esa tradición sumaron su sentido religioso. Esto es lo que explica que los testamentos hubieran tomado tal arraigo entre la población indígena mesoamericana. Los primeros testamentos de indígenas que se conocen corresponden a 1531, una época demasiado temprana, que enseña el rápido éxito de los evangelizadores.

Los indígenas que hicieron estos testamentos tenían nombres propios, nombres hispánicos. Estos nombres tienen una asociación con el santoral cristiano. Entre las mujeres el más corriente es el de María, sólo o compuesto. También el de Catarina, Ana, Magdalena, Juana, Francisca, Isabel y Paula. Entre los hombres los más corrientes eran los de Pedro, Pablo, Juan, Nicolás, Francisco, Santiago, Agustín, Diego, etc. Nombres que fueron introducidos por los religiosos y que eran asignados en el momento del bautismo. El nombre de Jesús, fue un nombre muy tardío entre los católicos. No todos los indígenas llevaban apellidos, muchos sólo tenían el nombre. Otros tenían por apellido el nombre del pueblo del que eran originarios. Aunque en el caso de México se mantenían vigentes muchos apellidos tradicionales. Y otros tantos llevaban el apellido de sus amos, sin que ello significara que fueran sus hijos. Nombre y

\footnotetext{
${ }^{13}$ ROJAS RABIELA, Teresa; REA, Elsa Leticia Rea; e MEDINA, Constantino. Vidas y Bienes Olvidados: Testamentos de Indígenas Novohispanos. 3 volúmenes. México: CIESAS, 2000, p. 26.

${ }^{14}$ ROJAS RABIELA, Teresa y otros. Op. Cit. p. 16.
} 
bautismo, nos aluden a algunos de los mecanismos esenciales utilizados por la iglesia para la incorporación de los indígenas al nuevo orden cultural.

En los testamentos de los indígenas americanos que conocemos también descubrimos una amplia gama social y estamental. Tanto hay testamentos de nobles y caciques, como de macehuales o comunes. Los hay de ladinos y chontales, incluso de yanaconas. Tanto hombres como mujeres testaban en una proporción diversa, que ameritará un comentario más adelante. Indígenas de diversos oficios testan: labradores, comerciantes, tejedoras, hilanderas, chicheras, sastres, carpinteros, zapateros, albañiles, constructores y pintores.

Con todo, tal parece, los testamentos fueron una poderosa herramienta para defender los derechos sobre predios y lotes, tanto rurales como urbanos. Los testamentos sirvieron para manifestar derechos antiguos, o adquiridos, sobre posesiones rurales, y para defenderlos de los encomenderos, los hacendados, las autoridades españolas, la comunidad y vecinos. En los testamentos, si bien se observan los principios de comunidad, su defensa, también se pueden ver los conflictos de los indios con las autoridades españolas y con la comunidad. Esto indica el panorama diverso que enfrentaban las comunidades indias. Unas regiones donde con mayor fortaleza se conservaron los vínculos comunitarios y las lealtades hacia los caciques, y otras donde la atomización, el fraccionamiento y la individualización aparecieron primero. En éstas segundas, que fueron muchas, y entre los indígenas de la ciudad, es muy claro advertir la conciencia de la importancia de la propiedad privada. Más allá de la retórica jurídica, estos testamentos enseñan la asimilación de los indígenas de un sentido práctico en el que nombrar linderos, particiones, bienes indivisos e hipotecas resultaban sustanciales en su existencia.

Un asunto importante de los testamentos de Bogotá, Santiago y Cuenca, es que fueron dictados por los indígenas y copiados por escribanos españoles. Aunque en muchos casos los escribanos requirieron un lengua (traductor). Mientras que en el caso de México muchos fueron escritos directamente por los indígenas en su idioma, fuera nahuatl (mexicano), otomí, zapoteco o mixteco. En ocasiones estos testamentos fueron escritos por escribanos indígenas que residían en los pueblos indios. Fueron esos mismos escribanos bilingües los que tradujeron muchos testamentos al castellano. Claro está, otros testamentos fueron dictados a escribanos españoles. La presencia de escribanos y traductores en los testamentos ha llevado a interrogarse sobre quién realmente habla en el testamento. Surgen innumerables interrogantes sobre si la voz de 
los indígenas no es suplantada por la del escribano y el traductor. O cuando menos alterada, transformada, adaptada. Es una cuestión muy difícil de establecer. ¿A quién pertenece, por ejemplo, la expresión, “...ya se contentó mi corazón, ya no me apura nada.." (queriendo decir que ya está preparado para la muerte), a su testador, un indígena del pueblo de Metepec, o a su testador? En cierto sentido se percibe una mayor flexibilidad en los testamentos elaborados en los campos y en los pueblos indígenas. En ellos, por ejemplo, el testamento no iniciaba con la clásica expresión "In Nomine Dei", o "En Nombre de Dios", sino con "Señor Nuestro". Con todo, bien sabemos hoy, el lenguaje fue un campo de intensa reelaboración durante los siglos XVI y XVII. El nahuatl apropió términos castellanos, el castellano apropió términos nahuatl, quechuas, muiscas y aymaras, en las distintas regiones de colonización.

Los indígenas que testaron fueron, por supuesto, un pequeño número de la población indígena de la época. Quizá los más vinculados a la cultura de los colonizadores. Con todo, los testamentos son documentos excepcionales. Son síntesis, pequeñas biografías de los indígenas que vivieron una de las épocas más caóticas, cambiantes y dramáticas de la historia moderna.

\section{¿Qué nos informan los testamentos de los indígenas?}

De manera preliminar quiero comentar algunos aspectos que me parecen bastante sugestivos de la lectura de las tres colecciones de testamentos señaladas. La selección hecha por los investigadores mexicanos al componer su colección privilegió los testamentos rurales. Todos proceden del mundo rural. Fueron hechos por indígenas que vivían en los poblados de la periferia de ciudad de México, o en regiones más acentuadamente etnicas como Tlaxcala, Cholula, o Oaxaca. Vivían en el campo, en el pueblo indio, y su actividad principal era la agricultura. Sin embargo, esto no quiere decir que, en el caso mexicano, no se hubieran dado testamentos de indígenas en la ciudad. Todo lo contrario, bien sabemos que la presencia de indígenas en la ciudad de México es anterior a la conquista y que el volumen de población indígena urbana en el siglo XVI fue enorme. Esta ausencia o desequilibrio en la compilación de los investigadores del Ciesas sólo puede indicarnos dos cosas: la dimensión y riqueza de los pueblos indígenas mexicanos y la gran avanzada de los misioneros en ellos, aun de zonas apartadas ${ }^{15}$.

Por el contrario, los testamentos de Bogotá, Santiago y Cuenca tenían un innegable acento urbano. Fueron hechos principalmente por indígenas arrai- 
gados en la ciudad, con excepción de los elaborados por caciques que mantenían un fuerte vinculo con su comunidad. Es decir, los de Bogotá, Santiago y Cuenca eran indígenas urbanos. Sus testamentos son clara evidencia de su aculturación y sincretismo cultural. Fueron hechos, podríamos decir, por los indígenas que más temprano y rápidamente se aculturaron. Fueron los indígenas que arraigaron en la ciudad. Unos llegaron con los conquistadores, otros fueron llevados a la ciudad por los encomenderos como indígenas de servicio, otros fueron ocupados en ellas levantando edificaciones y puentes por las autoridades españolas, y otros llegaron a la ciudad, abandonando sus comunidades, para huir del tributo. Recordemos que las ciudades hispanoamericanas se construyeron con el trabajo indígena. Indígenas que ya existían antes, o que, como en el caso de Bogotá, Lima y Santiago se trasladaron a ellas.

\section{La migración}

Un hecho sumamente interesante que descubren los testamentos indígenas del siglo XVI es el fenómeno de su migración. Es sabido que las sociedades indígenas antes de la conquista no eran estáticas, que tenían desplazamientos en razón de su expansión militar. También que había unos circuitos mercantiles, en los que mercaderes se trasladaban de unas regiones a otras. Con todo, estos movimientos eran regionales. A raíz de la conquista, y de la incorporación en forma forzadas de elevados contingentes de indígenas en esas empresas, muchos indígenas llegaron a recorrer impensables distancias. Por ejemplo, sabemos de indígenas aztecas y nicaraguas en la conquista del Perú. El primer matrimonio católico ocurrido en las goteras de Santafé de Bogotá ocurrió entre un soldado español y su indígena manceba de nacionalidad mexica. En esta ciudad, al menos el 10\% de los testamentos fueron hechos por indígenas originarios o descendientes de los incas. La gran mayoría llegaron con el conquistador Sebastián de Benalcázar, que luego de hacer la empresa en el norte del Perú (Ecuador) se dirigieron al norte hasta alcanzar la meseta donde se fundó Bogotá. Por otras fuentes, sabemos que algunos indígenas, que no dejaron testamento,

\footnotetext{
${ }^{15}$ Aunque también podemos encontrar un cierto sesgo procedimental del proyecto del Ciesas, que desde el inicio estaba orientado a la recopilación de información referida al problema agrario y la propiedad territorial. Cuando se reúnan los testamentos de los indígenas de Ciudad de México se tendrá un material valiosísimo para observar la formación de la más grande y compleja sociedad de Hispanoamérica.
} 
se decían pertenecer a la nobleza incaica. Luego de la conquista continuaron llegando indígenas del sur, procedentes del Perú y Ecuador, que llegaban a Bogotá como sirvientes y cargadores de funcionarios y mercaderes. Aunque, otros, por su cuenta, iban y venían dedicados a mercadear los magníficos productos peruanos. La influencia inca y sobre todo quechua en la cultura colombiana empieza a explorarse. En el habla es bastante notable, tanto que ya existe un diccionario de quechuismos. También en las técnicas de los textiles, carpintería y gravado y decoración de maderas y metales dejaron una impronta imborrable.

En el caso de Santiago los testamentos enseñan una presencia Inca, especialmente de indígenas del Cuzco, mucho mayor. El 28\% de los testamentos santiaguinos son de indígenas incas. Se trata de una proporción sumamente elevada, de enorme trascendencia en la formación de la sociedad chilena. La mayoría de los testamentos eran de indígenas mapuches, del centro y sur de Chile. También unos pocos eran de la región de Mendoza, Argentina. Los indígenas incas llegaron a Chile con los conquistadores y con los oficiales de la corona. Recordemos que en Lima tenía asiento la capital del Virreinato. El temor hacia los araucanos y el desprecio hacia los mapuches, es probable que haya conducido a una mayor valoración de los incas. Ciertamente, sobre los indígenas cuzcos la misma Corona creo una imagen de nobleza y distinción.

Finalmente, Lima, dada su condición de ciudad nueva, vivió el asentamiento de muchos indígenas forasteros. Distintos grupos indígenas, entre ellos los cuzcos, aportaron mano de obra para la construcción de la ciudad. En el momento que se realice un inventario de los testamentos de los indígenas de la ciudad se observará este fenómeno con claridad. Por el momento, vale subrayar que un censo realizado en Lima en 1613 indica que el 95\% de los indígenas de la ciudad eran forasteros ${ }^{16}$.

\footnotetext{
${ }^{16}$ Una primera observación al caso de Lima puede verse en CHARNEY, Paul. "Negotiating Roots: Indian migrants in the Lima Valley during colonial period". En The Indian in Latin American History: Resístance, resilience and acculturation. John Kicza (Editor). Wilmington: Jaguar Books, 2000. Para una fecha un poco más tardía (1690), Ann Wightman encontró que el $47.4 \%$ de los trabajadores indígenas de Cuzco eran foráneos. Ver, WIGHTMAN, Ann. "... residente en esa ciudad...: urban migrants in colonial Cuzco". En Migrants in Colonial Spanish America, David Robinson (Editor). Cambridge: Cambridge University Press, 1990.
} 


\section{La ciudad}

Los testamentos tienen la cualidad de acercarnos a una reflexión sobre los orígenes de las ciudades americanas. Siendo la población mayoritaria en ellas resulta lógico entender su aporte a su construcción y desarrollo. Ahora, los testamentos nos refieren más que a la ciudad a la parroquia, al barrio. Estos indígenas corrientemente se concentraron en lo que fueron luego los barrios indígenas de las ciudades. En Bogotá, en los barrios Las Nieves, Santa Bárbara y San Victorino; en Lima, en El Cercado y San Lázaro; y en Santiago en La Cañada, desde muy temprano se asentaron contingentes de indígenas. Como he señalado arriba estos indígenas llegaron a través de distintas modalidades. Unos adquirieron, pero también, muchos recibieron lotes y solares de sus amos. Bien como legados testamentales, o como simple gratificación por los servicios recibidos, y probablemente como una manera de arraigar una fuerza de trabajo en la ciudad, los españoles dieron títulos de propiedad a los indígenas. Cabe destacar que las construcciones referidas por los indígenas en los primeros testamentos hablan de bohíos redondos, es decir a la manera indígena. Esto quiere decir, que el paisaje urbano, en lo que respecta a estos barrios se parecía más al de las comunidades indígenas que al de las ciudades hispánicas. Hecho que no nos muestran las pinturas y grabados de las ciudades coloniales; tal vez porque la mayoría corresponden al siglo XVII, cuando distintas disposiciones las habían ajustado a los patrones peninsulares.

Debemos pensar que el establecimiento de las comunidades regulares y la construcción de sus parroquias fue posterior a la formación de las barriadas. Pero fue con ellas que adquirieron identidad. En todos los testamentos las personas reconocen que más que pertenecer a una villa o una ciudad, pertenecían a una parroquia. Para lo que había fuertes razones que adelante explicaré. Los oficios que realizaban estos indígenas eran los que requería la ciudad: construcción, sastrería, zapatería, hilandería, tejeduría, panadería, etc. Aunque no encontramos a los indígenas como propietarios de pulperías si lo eran de pequeñas tiendas. Sobresale el hecho de mujeres indígenas que tenían mesones en los que atendían una clientela variada de indígenas, mestizos y también blancos pobres. Igualmente, en toda Hispanoamérica las mujeres indígenas controlaron la producción y distribución de la chicha, la bebida de los indígenas. Llamadas chicheras, estas mujeres comprenden un sector socio profesional particular.

Conviene recordar también, que en las casas de los españoles residía una población indígena numerosa. No fueron pocas las ocasiones en las que las 
autoridades llamaron la atención sobre el excesivo número de sirvientes domésticos, y el trato indebido que les daban. Además, los indígenas que residían en sus barrios, no vivían concentrados en ellos. Por sus oficios, mujeres y hombres circulaban las calles. Esto nos hace pensar que la ciudad colonial de los primeros tiempos en buena medida fue indefectiblemente un escenario indígena. Pero señalar este hecho, siempre debe estar ligado al de los intensos procesos de mestizaje que se vivían en las ciudades.

\section{Religiosidad y cofradías}

Lo testamentos nos informan de una variedad de devociones y sentimientos religiosos de los indígenas, la mayoría de ellos ligados al tránsito de la muerte. Los indígenas, al igual que los otros grupos sociales de la época, invirtieron sus recursos en conseguir un sepelio digno, en ocasiones con pompa, y en asegurar su más allá. Por ejemplo, todos piden que su cuerpo sea amortajado de cierta manera. Y que el día que su cuerpo sea llevado de su casa a la iglesia lo acompañe una cruz. Representando la presencia de Cristo crucificado. Pero había dos posibilidades: cruz alta o baja. La primera era una cruz de dos metros, la segunda no superaba la cabeza del cura que la portaba y era más económica. La segunda era preferida por los pobres, pero también por los que querían dar muestras de humildad cristiana.

Sin embargo una devoción que hasta ahora ha sido muy poco estudiada, es la de la pertenencia de los indígenas a las cofradías de culto. Las cofradías eran una organización de origen medieval, que reunía fervientes devotos. Su propósito fundamental era custodiar y venerar la imagen del santo, pero además velar y socorrer por el alma de los hermanos cofrades. Sin embargo, la esencia de estas cofradías era asistir a sus miembros en el momento de la agonía y la muerte. Sus mayordomos y familiares visitaban al enfermo, y cuando fallecía lo acompañaban en el velorio, cantaban y oraban en su sepelio. Después lloraban y rezaban por su alma. Cada santo o santa, y sus advocaciones tuvieron sus cofradías. Es decir, en cada iglesia o parroquia tenían asiento muchas cofradías. Hubo cofradías de peninsulares y de criollos, es decir de la gente blanca, y en algunas ciudades hubo cofradías de grupos regionales, las que reunían a los vascos, por ejemplo, y rendían devoción a Nuestra Señora de Aranzazu o a San Benito Abad. Hubo cofradías étnicas, de indígenas y negros. Uno de los distintivos del catolicismo del siglo XVI, presente en los indígenas y en los demás grupos, es el fervor y devoción a las santidades. Se trataba, en cierta 
medida, a que ofrecía en el santo un intermediario, una entidad próxima al dolor de los mortales.

Resulta llamativo que las cofradías hubieran arraigado tanto entre los indígenas. Cada indígena pertenecía a una, o varias cofradías. En ocasiones hubo quienes pertenecieron a más de una, tanto como siete u ocho cofradías. Entre los indígenas las más populares eran la del Santo Rosario, Santa Lucía, Nuestra Señora de las Nieves, Nuestra Señora de Copacacabana, Nuestra Señora de Guadalupe, Nuestra Señora de los Remedios, Nuestra Señora de la Candelaria, Nuestra Señora del Campo, Cristo Crucificado, San José, San Agustín, San Francisco, el Santísimo Sacramento, Las Ánimas del Purgatorio y la de la Santa Veracruz. Las últimas promovidas por los franciscanos. La entrega de los indígenas a las cofradías es comprensible puesto que fue el canal a través del cual los misioneros los atraparon a sus parroquias. Su estrategia principal de evangelización se dirigía a la vecindad, la cual terminaban conociendo fielmente. A esa feligresía de vecinos dirigían sus prédicas, la confesión y comunión, y demás sacramentos. Finalmente, eran atraídos hacia las cofradías.

Las cofradías eran organizaciones estables, que contaban con su mayordomo y tesorero. Los aportes de los hermanos proveían de un capital considerable a las cofradías. No cabe duda, que las cofradías eran efectivas redes sociales. Proveyeron el vínculo más estable y duradero a los indígenas en su proceso de establecimiento en la ciudad. En las cofradías los indígenas encontraban solidaridad y asistencia espiritual, elemento que sin duda mantuvo su voluntad en una época caos y cambios vertiginosos. No sabemos aun cuantos elementos étnicos indígenas aparecían en sus formas de culto. Cuanto de la utilización de agua, copal, flores y cantos en las fiestas de las cofradías era una tradición prehispánica, compartida con el catolicismo. Con todo, cuando hablamos de la fe, creencia y devoción de estos indígenas, no quiero afirmar que fuera perfecta en el sentido de la ortodoxia católica. Toda vez que, bien lo sabemos, durante mucho tiempo sobrevivieron formas de culto clandestinas, y en la vida cotidiana tanto ritos como supersticiones se conservaron. La occidentalización y catolización de los indígenas deben verse entonces como procesos y no como hechos terminados.

Además las cofradías presentaban una cierta división de género. Las de la ciudad fueron administradas por mujeres. Ellas fueron el grupo más dinámico de la religiosidad urbana. En cambio, en el campo, en los pueblos indios, los hombres controlaban las mayordomías. En el pueblo indígena la cofradía era un espacio, un poder que competía con el dominio tradicional de los caciques. 
Pero si las cofradías nos enseñan elementos comunitarios, no podríamos olvidar que uno de los aspectos más incisivos de la evangelización era la individualización de los indígenas. Es decir, que se asumieran como individuos autónomos y racionales, capaces de discernir entre el bien y el mal, entre Dios y el demonio. El testamento es la concreción cultural de ese logro. En él el indígena habla en primera persona "Yo fulanito de tal...", "Mando y ordeno...". El testador se reconoce persona, en el sentido de la tradición cristiana y romana, y no como alguien que pertenece a una comunidad indiferenciada y homogénea. Aquí el indígena se reconoce como sujeto de derecho, por ejemplo el de poseer sus bienes. Lo sobrenatural cristiano de que nos habla S. Gruzinski ${ }^{17}$, constituye el más firme amarre entre el alma y el cuerpo, fundamento de la estrategia de conversión de los naturales. Y en el que, a pesar de todos los sincretismos dados, los religiosos lograron sus mayores victorias

\section{Las mujeres indígenas}

Los testamentos de mujeres comprendían una proporción bastante significativa del total relativos a indígenas que se hacían en cada ciudad. En Santafé de Bogotá eran el 70\%, en Cuenca (Ecuador) el 50\%, en Santiago de Chile el $45 \%$, en México el 35\%. En el caso de Santiago, el menor porcentaje obedece a que entre los migrantes incas al Reino de Chile el número era acentuadamente masculino. Y en el caso de México, como ya dijimos, la muestra publicada toma en cuenta más a los indígenas del campo que a los de la ciudad. Con todo, estas cifras muestran un hecho incontrastable, la fuerte presencia femenina en las ciudades y en el proceso de formación de la nueva sociedad. Las ciudades hispanoamericanas tuvieron una mayoría de población femenina durante los siglos XVI y XVII. En el siglo XVIII esa diferencia se redujo, sin llegar a igualarse. Con cierta razón alguien dijo que esas eran "ciudades de mujeres". La explicación de este particular hecho es el de que las ciudades hispánicas absorbieron preferentemente fuerza de trabajo femenina de su entorno destinado al servicio doméstico. Pero también porque éstas en principio no estaban obligadas a pagar tributo.

${ }^{17}$ GRUZINSKI, Serge. La Colonización de lo Imaginario: sociedades indígenas y occidentalización en el México español. Siglos XVI-XVIII. México: FCE, 1991. 
La ciudad ofrecía a las mujeres indígenas atractivas posibilidades de conseguir numerario y alcanzar una independencia que no tenían en los pueblos. Por eso las actividades en las que las mujeres indígenas sobresalieron fueron las del comercio. En todas las ciudades el comercio informal y la venta de alimentos estaban en manos de las mujeres indígenas. Conocidas como "gateras" o "regatonas", en todas las ciudades eran las que vendían frutas, fritos, dulces y panes en forma ambulante. También vendían hierbas medicinales y aromáticas, velas, leña y chicha. Las más prósperas dejaban de andar las calles y abrían una tienda. Estas vendedoras llegaron a ser una fastidiosa competencia para los tenderos organizados, que se quejaban de ellas por que por no pagar impuestos ofrecían los productos a menor precio. En los barrios indígenas casi en cada dos casas había una pequeña tienda. He dicho que otras indígenas abrían sus mesones a manera de restaurantes. Y otras más emprendedoras aun, efectuaban un comercio regional llevando sus productos, incluyendo textiles, a las regiones mineras. A saber por los testamentos, muchas mujeres participaban también en el crédito financiero, prestando pequeñas sumas de dinero a indígenas, mestizos y blancos. Finalmente, en Cuenca, Ecuador, parece que las indígenas destinaban sus ahorros a adquirir predios tanto urbanos como rurales, pues su participación en el mercado inmobiliario es sorprendente. Entre un $28 \%$ y un $40 \%$ de las compras-ventas de terrenos del siglo XVIII fueron realizados por ellas ${ }^{18}$.

Pero, era verdaderamente nueva esta presencia de las mujeres en las actividades mercantiles, o se trataba de una continuidad prehispánica? ${ }^{19}$ Distintos códices prehispánicos nos enseñan a las mujeres mexicas con sus ventas en los tianguis. Y Fray Bernardino de Sahagún, observador como ninguno de las costumbres de los indígenas mexicas, describió los multiples oficios que desempeñaban. En el tianguis vendían tejidos, mantas guisos, tamales, tortillas, chocolate, plantas medicinales y aromáticas. Y también hacían el llamativo

\footnotetext{
${ }^{18} \mathrm{Al}$ respecto ver POLONI-SIMARD, Jacques. "Mujeres indígenas y economía urbana. El caso de Cuenca durante la colonia". En Mujeres de los Andes: condiciones de vida y salud. Defossez, Bassin y Viveros (editores). Bogotá: Universidad Externado de Colombia - Ifea, 1998. pp. 201-221.

${ }^{19}$ Agradezco esta inquietud a Sheila de Castro Faria. SAHAGÚN, Fray Bernardino de. Historia General de las Cosas de Nueva España, 2 vols., introducción, paleografía y glosario de Alfredo López Austin y Josefina García. Madrid: Alianza Editorial, 1988.
} 
baño de shampoo y masaje que aplicaban al cabello de hombres y mujeres. Sin embargo, aunque parecían dominar el tianguis, es decir, el mercado local, no nos es clara su participación en el comercio en gran escala.

La actitud de las mujeres indígenas como propietarias de predios y solares llega a ser sorprendente. No son pocas las que nombraban haber recibido de sus amos el lote en el que residían. Algunas reconocían haber tenido prole con ellos. Lo importante a resaltar es la conciencia que parecían tener estas mujeres del valor de la propiedad privada en la sociedad en que vivían. Y la intuición de que sus títulos de propiedad eran el más preciado patrimonio ante la adversidad y la pobreza. Es eso lo que parecerían revelar las fuertes cláusulas que ponían a sus legados testamentales para impedir que sus hijos los vendieran. Especialmente con los hijos “calaveras”, los que habían caído en el alcohol o en el juego. Así, decían dejarles el bohío o el solar para que vivieran en él, sin que jamás pudieran venderlo, porque era lo único que les quedaba!

Los testamentos enseñan la adopción del modelo familiar introducido por los religiosos. El matrimonio católico se había difundido ampliamente entre los indígenas y las líneas de sucesión de primogenitura se habían consolidado. Por ejemplo, la mayoría de las mujeres que dejaron testamento eran viudas, pero todas se habían casado por lo católico (aunque también tuvieron hijos naturales antes de sus nupcias o en su viudez). Algunas como he dicho tuvieron hijos de españoles. Las solteras fueron un grupo menor, que tampoco estaban eximidas de haber procreado con españoles o indígenas. La familia indígena que nos presentan los testamentos es sumamente compleja, difícil de precisar. De manera preliminar podríamos decir que es una familia que vivía una fractura, un desgarramiento, que no alcanzamos a conocer en toda su extensión. Las familias separadas, los ancestros perdidos, la reducción del parentesco, la alta mortalidad, especialmente infantil, limitaban ostensiblemente su vida familiar. La unión conyugal era precaria, aunque en algunos casos demostraba una fortaleza singular; como en el caso de una indígena de Bogotá que se dedicaba a comerciar en tierra caliente para sostener la familia ya que su marido era tributario, o la que amasando pan mantenía la casa debido a la enfermedad de su esposo.

A pesar de todo, los hogares indígenas eran el colchón que amortiguaba los quebrantos que vivía la sociedad colonial. Muchos testadores confesaron haber criado niños abandonados o huérfanos, casi como hijos propios. Sorprende además que, en ocasiones, esos niños fueran blancos. Cada testamento descubre un tejido de relaciones de solidaridad, de ayuda, de caridad, sumamente importante. Fue gracias a este tejido que pudieron sobrevivir, cierto es penosamente, 
muchas viudas, ancianos, o niños sin padre. En los testamentos abundan los encargos dirigidos a familiares o a vecinos para velar por los que ya no se podrá proteger, especialmente hijos descarriados (bebedores, jugadores o enfermos). También están ahí las constancias de gratitud para los que en momentos críticos del ciclo vital brindaron auxilio y ayuda, en ellas se revelan en forma intensa los vínculos cambiantes que tempranamente establecieron los indígenas con los negros y mulatos. De ser sus amos, en ocasiones, tornaron a ser sus vecinos y parientes. En la base de esa vida familiar, de esas redes de solidaridad, es bueno decirlo, se encontraban mujeres sumamente activas y concientes del momento histórico que vivían.

\section{El mestizaje}

Los testamentos de los indígenas ilustran de manera excepcional el mestizaje americano. Como he dicho, el propio documento en muchos casos fue adaptado, y también traducido. En las áreas rurales de algunas regiones, como México y los Andes, era redactado por escribanos indígenas o maestros de capilla. Los indígenas que escribieron testamentos fueron los que más cerca y activamente vivieron la conversión y la adopción de los valores hispánicos y católicos. Probablemente fueron los que más intimaron con los españoles y los que recibieron en forma más sistemática la doctrina de los misioneros. Sin embargo, aunque los indígenas varones continuaron más arraigados a la tierra y a las actividades tradicionales, fueron las mujeres indígenas las que desempeñaron un papel más activo en el mestizaje. Al respecto, cabe recordar el papel prominente de La Malinche en el proceso de la conquista mexicana. Traductora, amante de españoles y madre de mestizos, La Malinche representa el más elevado símbolo femenino en el establecimiento de la sociedad colonial. Con el tiempo, las actividades domésticas acercaron a las mujeres indígenas a las costumbres españolas. De hecho, aprendieron la nueva lengua y cambiaron sus formas de vestir. Por sus actividades mercantiles y el intenso contacto que tenían con todos los grupos sociales, las mujeres indígenas fueron un puente, un intermediario cultural entre el mundo indígena y el de los peninsulares. Por la movilidad que tenían, tanto espacial como culturalmente, las mujeres indígenas supieron aprovechar las ventajas que daban las fisuras del orden colonial. He dicho también, que fue en razón del contacto entre los peninsulares y los indígenas, que creció tan precipitadamente el mestizaje. Una experiencia compleja, diversa, cuyo resultado fue el de la formación una sociedad sincrética. 
Un aspecto importante de comentar es el del espectro social con el que se relacionaban los indígenas ${ }^{20}$. Lo hemos visto en relación con los deudores. Pero también puede verse en relación con los testigos de los testamentos. Según sea la ubicación y la red social de estos indígenas sus testigos eran indígenas, o mestizos, o españoles. De hecho los testamentos de los indígenas del campo presentan una mayor frecuencia de testigos indígenas. No así los de la ciudad, que o son una combinación de unos y otros, o son exclusivamente de blancos. Aunque esta última circunstancia se daba entre los indígenas que habían alcanzado una posición en la ciudad.

Otro campo en el que puede observarse con propiedad el sincretismo en curso es en aquello que podríamos llamar la cultura material, aspecto en el que son ricos los testamentos. Efectivamente, los inventarios de mobiliario doméstico y vestuario son testigos de la adopción de nuevos patrones cotidianos adoptados por los indígenas. Basta observar la presencia de sillas, camas, almohadas, ropa de cama, camisas de lienzo. En algunos casos hemos encontrado vajillas chinas entre los indígenas mexicanos. $\mathrm{O}$ algo bastante especial, el caballo, que sólo estaba permitido a los caciques. Es más, libros de doctrina cristiana e historia universal aparecen en los inventarios de algunos indígenas. En fin, el medio doméstico de los indígenas de la ciudad era un universo sincrético. No de manera absoluta y total, por supuesto. Debemos ver el medio indígena como una realidad más variada y compleja que la que nos lo presenta compuesto por caciques e indígenas. Entre ellos tenía lugar una constelación de realidades sociales, especialmente exacerbadas por las ciudades españolas. Allí la mixtura social dio lugar a lo que entonces se llamó la plebe, grupo al que cada vez más las élites estigmatizaron y temieron. Hemos visto cuan distinta fue la vida de las mujeres del campo a las de la ciudad, y en la ciudad la variedad de experiencias que podían vivir. Por supuesto, no todas felices ni faltas de dolor, pero fue en las ciudades donde descubrieron y construyeron un destino distinto.

\footnotetext{
${ }^{20} \mathrm{Al}$ respecto, Jacques Poloni-Simard postula el elemento relacional como la clave para comprender el mundo indígena colonial. Ver su decisivo articulo: "Historia de los indios en los Andes, los indígenas en la historiografía andina: análisis y propuestas", en Anuario IEHS, Tandil, Argentina, No. 15, 2000, pp. 87-100.
} 


\section{Conclusión}

Los testamentos dejados por los indígenas de las distintas regiones de América constituyen un legado excepcional, sobre el que los historiadores apenas empezamos a tomar conciencia. Más que inusuales, los testamentos de los indígenas rompen las visiones esquemáticas del pasado colonial. Especies de pequeñas biografías, los testamentos de los indígenas constituyen un material invaluable. Ellos permiten conocer trayectorias sociales muy diversas: las de hombres y mujeres, caciques y macehuales, indígenas de la ciudad, diversos oficios, etc. Nos informan de lo material y lo espiritual, lo público y lo privado de este grupo social en un momento tan complejo de su historia. La demografía histórica construyó un gran telón de fondo del siglo XVI que fue el derrumbamiento de las sociedades indígenas y la catástrofe poblacional. Los testamentos de indígenas nos permiten ahora observar los distintos procesos ocurridos sobre ese telón de fondo: migración, sincretismo, movilidad social, nuevos patrones femeninos, lazos con el viejo sistema comunitario, y especialmente, los procesos de continuidad y cristalización del nuevo orden social.

Finalmente, gustaría llamar la atención sobre la lectura que conviene hacer de esta documentación. Un historiador o un antropólogo puede encontrar datos de interés en un testamento. Como quien saca un pez del agua. Más interesante aun, puede hacer una lectura sistemática de este corpus y encontrar hechos regulares. A partir de ellos puede construir hipótesis de orden económico, social o cultural. Aunque esa lectura debería combinarse con la atención a lo irregular, a lo incidental, a lo excepcional de la información. Éstos, que podríamos llamar indicios, pueden llevar a cotejar o precisar nuestras ideas consolidadas. También pueden servir para intuir nuevas interpretaciones de fenómenos sociales locales. Con todo, cabe recordar que los testamentos no son un corpus documental total, autosuficiente, y que siempre requerirá complementarse con otra documentación. 